\title{
Plasma Treatment of Polymer Surfaces in Gas Mixture
}

\author{
D. M. Svirachev, N. A. Tabaliov \\ Faculty of Physics, University of Sofia, 5 J. Bourchier Blvd., 1164 Sofia, Bulgaria
}

Received 8 February 2004

\begin{abstract}
In the present work the plasma surface modification of the polyethylene terephthalate is researched. It is realized in the RF-capacitive discharge. The modification in the flowing regime of the discharge is carried out for the following gas mixtures $\mathrm{Ar}-\mathrm{O}_{2}, \mathrm{CF}_{4}-\mathrm{O}_{2}$ and $\mathrm{CF}_{2} \mathrm{Cl}_{2}-\mathrm{O}_{2}$. The time of treatment of the discharge $t_{t r}$ is changed in the ranges $0,1-100 \mathrm{~s}$. The experimental results for the wetting contact angle $\theta$ and adhesion work $W_{a}$ are obtained as a function of the time $t_{t r}$ at a different percentage of the gas mixture. Several fields with defined character times are seen in dependence on the rate of change in the angle $\theta$ and the work $W_{a}$, which describes participation of several chemical kinetic processes. The qualitative analysis of the experimental results is made using different by their chemical compound functional groups, which are created and destroyed on the polymer surface at the time of treatment of the pattern in the discharge. The behavior and analysis of the experimental results in the presence of residual oxygen-containing gases shows that treating of the polymer material in pure gases should be interpreted with the same kinetic schemes as well as their mixtures with oxygen.
\end{abstract}

PACS number: 52.80. Hc, 82.35.Lr

\section{Introduction}

The gas emission in the reactor accounts for an unwished moment at the realization of the plasma-chemical treatment of polymer materials, because the qualitative composition of the reactor environment is changed, even it is uncontrolled. Reasons for gas emission are known. On the one hand, these are desorption phenomena from the surface and volume of the reactor, the polymer material and gas leakage of air in the discharge system from the atmosphere. On the other hand this discharge accounts for excellent means for gas cleaning of the walls, which limits it at the time of its burning. So, the reactor at the time of gas discharge will emit higher quantities of gas than those before the turn on of the discharge. As it was commented in [1], in the reactor the volume is emitted 
and oxygen-containing gaseous products (from type $\mathrm{O}_{2}, \mathrm{H}_{2} \mathrm{O}, \mathrm{CO}, \mathrm{CO}_{2}$, etc.) enter, which leads to their participation in the treatment of polymer materials together with the working gas. It's obvious that their unwished and uncontrolled participation makes extremely difficult the interpretation of the experimental results and the theoretical modeling of processes, which have a role at the treating of pure gases.

It is also well known [26] that in many of the plasma-chemical technologies with different gas mixtures in various combinations and proportions are used. Due to their highly active character, the oxygen is an inseparable part of this mixture, especially for technologies connected with the increase in adhesion properties, etching of various structures, restoring- oxidizing processes, etc. The increase in adhesion properties mostly happens by modification of polymer surface and the value of contact angle of wetting $\theta$ is accepted as qualitative criterion. The experimental results, which are connected with plasma modification, show a complicated behavior of the contact angle $\theta$. Very often these results are controversial with high deviation and are very difficult to be interpreted.

The facts and reasonings given above suggest that it is necessary the research, connected with plasma-modification in mixture of gases, where one of them is obligatory oxygen, be continued. Undoubtedly, such research can be of help for the empirical optimization of technological processes. Also, modification can be retraced more precisely at the transition from oxygen mixture to pure gases, which will help the experimental results to be completely and precisely interpreted and statistically processed.

\section{Experiment}

The experimental setup and the methodology described in [1] are used for the modification of the polymer surface and measurement of the contact angle $\theta$. The plasma modification of polymer surface is realized in RF-discharge with external electrodes (13.56 MHz), E-type. The input power in the discharge in the quartz camera is the same and equal to $100 \mathrm{~W}$ for all mixtures. The gas mixtures measured in gas-flowing regime are: $\mathrm{Ar}-\mathrm{O}_{2}, \mathrm{CF}_{4}-\mathrm{O}_{2}, \mathrm{CF}_{2} \mathrm{Cl}_{2}-\mathrm{O}_{2}$. Technical pure gases were used, whereupon the purity of the gases is $98-99 \%$. The total pressure of the gas mixture is $66.7 \mathrm{~Pa}(0.5$ Torr). Polyethylene terephthalate (PET) is used as a polymer material type Hostaphan R125 with thickness $125 \mu \mathrm{m}$. The measuring of the contact angle $\theta$ is realized using the projection system, and applying the method of sessile drop. Bidistilled and deionized water $\mathrm{H}_{2} \mathrm{O}$ is used as a pattern liquid. Five water drops are put on the films of PET. This gives the possibility for the measured contact angles from both sides of the drops to be averaged and to determine the mean value of $\theta$. The errors, which can occur after averaging all measures, are less than $\pm 1.5^{\circ}$ and for that reason they are not shown in the figures with the experimental results. 


\section{M. Svirachev, N. A. Tabaliov}

\section{The Experimental Results and Discussion}

The behavior of the contact angle and work of adhesion $W_{A}$ for gas mixture Ar$\mathrm{O}_{2}$ is shown in Figures 1 and 2 . The necessity for presenting the experimental results by the estimated adhesion work was discussed in [1]. The relation between $W_{A}$ and the angle $\theta$, is presented by the well-known equation of Young-Dupre $[7,8]$ :

$$
W_{A}=\sigma_{L V}(1+\cos \vartheta)
$$

Where $\sigma_{l v}$ is the surface tension of the pattern liquid.

The curves which connect the experimental points are processed using the spline approximation, but not averaged by methods of mathematical statistics. Why the similar presentation is used, it is discussed and analyzed in details in [1].

Despite of the percentage of the mixture a monotonous increase in $W_{A}$ is observed. The increase in the work $W_{A}$ suggests that the surface tension $\sigma_{s v}$ of PET has to increase, too. In that mixture there exist preconditions for the creation of oxygen-containing $(\mathrm{O})_{F G}$ functional groups as: $\mathrm{OH}, \mathrm{CO}, \mathrm{COOH}, \mathrm{OOH}$ etc. These functional groups take the place of carbon-hydrogen groups type: $\mathrm{C}_{6} \mathrm{H}_{6}, \mathrm{C}_{2} \mathrm{H}_{2}$, and $\mathrm{CH}$. So, the increase in $\sigma_{s v}$ comes mainly from the increase in the polar component $\sigma_{s v}^{p}$ of PET, which according to us, is a result from the increase in the number of possible hydrogen bonds, which can be realized between the two phases — solid and liquid, (polymer surface — pattern liquid).

The time of treatment $t_{t r}$, which ranges between $0.1-100 \mathrm{~s}$, depends on the rate of changing the work $W_{A}$. This changing conditionally can be divided into three parts: first $\left(t_{t r}=0.1-0.6 \mathrm{~s}\right)$, second $\left(t_{t r}=0.6-10 \mathrm{~s}\right)$ and third $\left(t_{t r}=10-100 \mathrm{~s}\right)$.

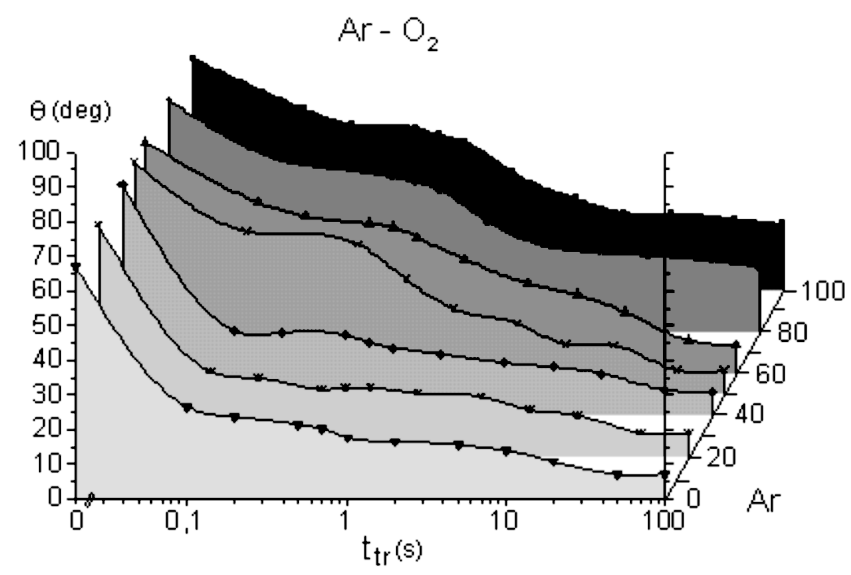

Figure 1. Behavior of the contact angle $\theta$ at the treatment time $t_{t r}$ or different percentages $\mathrm{Ar}-\mathrm{O}_{2}$. 
These boundaries, of course, should not be accepted and considered as exactly defined. Also, they change depending on the percentage proportion of the mixture. The introduction of these areas, however, makes easier the interpreting of experimental results, because every area will depend on a defined character time.

The presence of several character times for the whole time of treatment $t_{t r}$ suggests the participation of several chemical kinetic processes. In order to qualitatively interpret our results we will enter into two possible kinetic processes:

- Creating and destroying of different oxygen-containing $(\mathrm{O})_{\mathrm{FG}}$ functional groups.

- Creating and destroying of different carbon-hydrogen $(\mathrm{CH})_{\mathrm{FG}}$ functional groups.

As a result of the treatment of polymer surface in RF-discharge, these two functional groups will be continually in competition and their concentration will depend on external parameters, as well as on the time of treatment $t_{t r}$. We will accept that the change in the surface tension $\sigma_{s v}$ is realized only when $(\mathrm{O})_{\mathrm{FG}}$ group replace $(\mathrm{CH})_{\mathrm{FG}}$ group and conversely - it will not change, when it replaces another group with the same character. The increase (decrease) in $(\mathrm{O})_{\mathrm{FG}}$ groups, despite of the concrete chemical composition of the group leads to an increase (decrease) in the polar component $\sigma_{s v}^{p}$ with one and the same value. The same case is referred to as $(\mathrm{CH})_{\mathrm{FG}}$ groups, but they will affect the dispersion component $\sigma_{s v}^{d}$. So, at this stage no difference between various in chemical composition, but similar in functionality will be made.

As it can be seen from Figures 1 and 2, the changing of the angle $\theta$ and the work $W_{A}$ depends on the percentage proportion of the mixture. When the quantity of

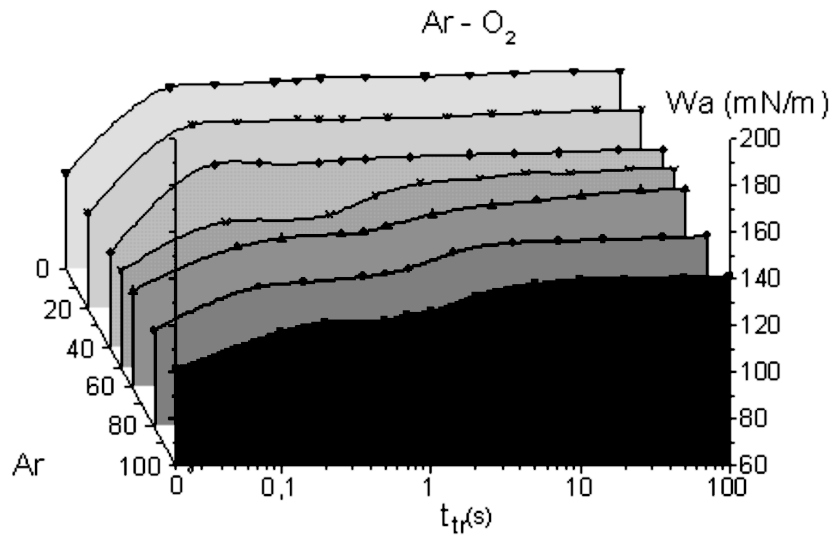

Figure 2. Behavior of the adhesion work $W_{A}$ at the treatment time $t_{t r}$ for different percentages $\mathrm{Ar}-\mathrm{O}_{2}$. 


\section{M. Svirachev, N. A. Tabaliov}

the oxygen is high (60-100\%), the basic change of the values $\theta$ and $W_{A}$ is at the first area $\left(t_{t r}=0.1-0.2 \mathrm{~s}\right)$. Below 50\%, when Ar begins to dominate, the basic change except in the first area is also in the second area, and character times are displaced to the higher values of $t_{t r}$ with the decrease in the percentage contents of $\mathrm{O}_{2}$. As it is shown in [1], in the second or in the third area at the time of treating $t_{t r}$ an etching process begins. The etching rate has to be proportional to $\mathrm{O}_{2}$ and to increase with the increasing of the oxygen concentration.

The character of the curves also shows that in the three areas of the time of treatment $t_{t r}$, the creation of $(\mathrm{O})_{\mathrm{FG}}$ groups dominates above the creation of $(\mathrm{CH})_{\mathrm{FG}}$ groups. The rates of creating these groups are different in those areas and highly depend on the percentage contents of $\mathrm{O}_{2}$. One can get the impression that despite the high changes of the oxygen from 0 to $50 \%$, the data are changed very little. One of the possible reasons for the low sensitivity towards quantity of oxygen is that for the modification little quantities of oxygen are necessary and the modification is controlled not only by the gas in the reactor volume, but also by the alloy oxygen-containing gases, which are emitted from the reactor, from the material volumes in the reactor and from the treated polymer.

An essential difference of changing the work $W_{A}$ (angle $\theta$ ), is observed in the interval 50-60\% contents of $\mathrm{O}_{2}$. These differences will be hardly explained by the increased quantity of oxygen, because up to $50 \%$ the different quantity of the oxygen does not render visible influence upon the surface tension $\sigma_{s v}$. In this case, the explanation is better to be searched in connection with the form and the quantitative composition of the discharge, which indisputably changes with the variation in the percentage proportion of $\mathrm{O}_{2}$.

As it is known, the parameters of RF-discharge and the micro-parameters of the plasma quantitative and qualitative are differentiated for the different mixtures [9,10]. When Ar dominates, it is cropped out as a basic plasma-creating gas and begins to give these parameters. As it is also known, the RF-discharge in argon, as every inert environment in comparison with the chemically active gas, is considerably more elementary from the physical and chemical processes and poorer from the point of view of the particles participating in these processes. When the $\mathrm{O}_{2}$ begins to participate and starts to dominate, then the plasma-creating gases are already two and at the same time in the discharge system the participation of very different products from that chemically active gas is intensified. In this way, the RF-discharge becomes more complicated process and richer of different particles in the dominating oxygen environment. At this state it is even possible for the whole kinetic scheme of influence upon the polymer surface to be changed, thus realizing the modification by other new channels and with other by quantity and composition components. For the clarification of these questions, however additional research is necessary, which is connected with plasma diagnostics.

The changing of the contact angle $\theta$ and the adhesion work $W_{A}$ are shown in Figures 3 and 4 for gas mixture $\mathrm{CF}_{2} \mathrm{Cl}_{2}-\mathrm{O}_{2}$. The degree of modification in that 


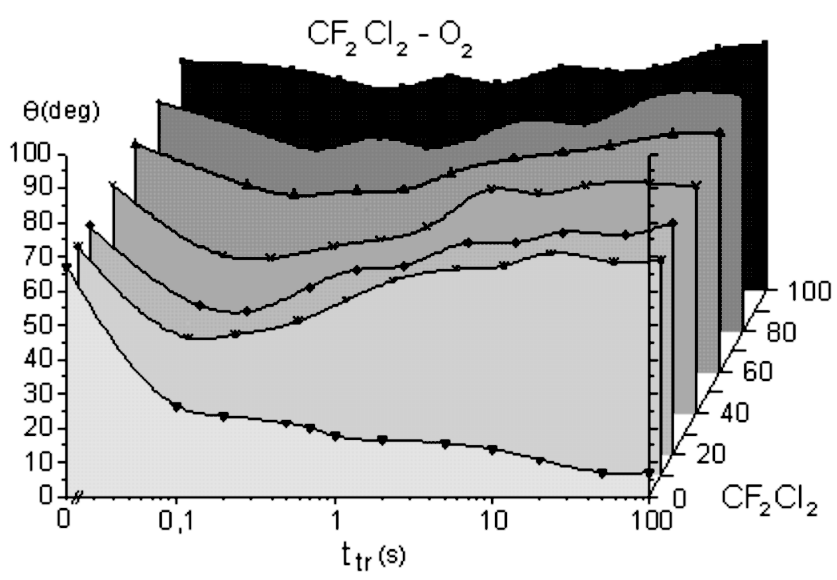

Figure 3. Behavior of the contact angle $\theta$ at the treatment time $t_{t r}$ for different percentages $\mathrm{CF}_{2} \mathrm{Cl}_{2}-\mathrm{O}_{2}$.

mixture shows another qualitative character. The work $W_{A}$ reaches certain maximal values, which depends on the percentage contents of freon 12 . The decrease in the percentage contents of $\mathrm{CF}_{2} \mathrm{Cl}_{2}$ leads to an increase of the maximum of $W_{A}$ increases and moves to the short times of $t_{t r}$. Only at the level of pure oxygen the monotonous increasing of the work $W_{A}$ is kept.

That behavior can be explained qualitatively with the assumed kinetic scheme. Of course, the scheme should be far more complicated and more than two examined kinetic processes are included. At the short times of treating $t_{t r}$ (in the

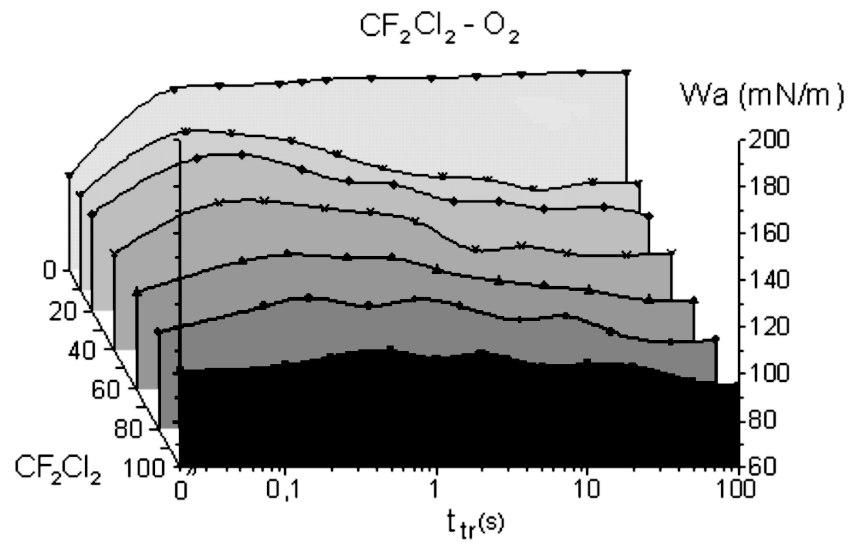

Figure 4. Behavior of the adhesion work $W_{A}$ at the treatment time $t_{t r}$ for different percentages $\mathrm{CF}_{2} \mathrm{Cl}_{2}-\mathrm{O}_{2}$. 


\section{M. Svirachev, N. A. Tabaliov}

first area $0.1-0.6 \mathrm{~s}$ ) the increase in $W_{A}$ is observed with different rate, which increases with the increase in the percentage contents of $\mathrm{O}_{2}$. It shows that the creation of $(\mathrm{O})_{F G}$ dominates over the creation of $(\mathrm{CH})_{F G}$, whereupon the polar component of surface tension $\sigma_{s v}^{p}$ increases. When the contents of freon 12 in the investigating mixture is high, then the adhesion work $W_{A}$ is changed a little. Unlike $\mathrm{r}_{-2}$ mixture (Figures 1 and 2), the presence of residual oxygen environment from gas emission does not render such high influence. One possible reason is chlorine atoms, which are very active too, like oxygen atoms.

The presence of active chlorine atoms in discharge plasma can depress the rising of $(\mathrm{O})_{F G}$ on the polymer surface as they create $(\mathrm{CCl})_{\mathrm{FG}}$ groups. The displacing of hydrogen atoms in PET with chlorine atoms will lead to an increase in $\sigma_{s v}$, but through the increase in the dispersion of $\sigma_{s v}^{d}$ component. The value of $\sigma_{s v}^{d}$ is also a result of the dispersion interaction of $\mathrm{Cl}$ atoms with the hydrogen molecule, and the value of $\sigma_{s v}^{p}$ - is also a result of the hydrogen bond of $\mathrm{H}$ and $\mathrm{O}$ atoms with the water. Then the absolute change for one functional group of $\sigma_{s v}^{d}$ should be considerably less than $\sigma_{s v}^{p}[11,12]$.

So, the change in $\sigma_{s v}$, when the $(\mathrm{CCl})_{\mathrm{FG}}$ groups are changed, is much lower than the variation of $(\mathrm{O})_{\mathrm{FG}}$ groups. In this way, the initial increase in the work $W_{A}$ in freon 12 can be due to the increase in oxygen-containing $(\mathrm{O})_{\mathrm{FG}}$, as well as to the increase in chlorine-containing $(\mathrm{CCl})_{\mathrm{FG}}$ groups. Unlike $\mathrm{Ar}-\mathrm{O}_{2}$ environment at the presence of freon 12 the creation of carbon-fluorine-chlorine $(\mathrm{CFCl})_{\mathrm{FG}}$ groups such as: $\mathrm{CF}_{2} \mathrm{Cl}, \mathrm{CF}_{2}, \mathrm{CFCl}$ etc. is possible. After reaching the maximal value of $W_{A}$, the groups, which contain fluorine-chlorine $(\mathrm{CFCl})_{\mathrm{FG}}$ groups, begin to displace the $(\mathrm{O})_{\mathrm{FG}}$ and $(\mathrm{CCl})_{\mathrm{FG}}$ groups, and this leads to a decrease in $W_{A}$, respectively $\sigma_{s v}$. The rate of decrease in $W_{A}$ is different and depends on the percentage contents of freon 12. The character times are displaced to shorter times of $t_{t r}$ with a decrease in the percentage contents of $\mathrm{CF}_{2} \mathrm{Cl}_{2}$. The highest relatively change of the work $W_{A}$ is observed at composites with low contents of freon 12 and it is realized in the first and the second areas of $t_{t r}$. As, $\mathrm{CF}_{2} \mathrm{Cl}_{2}$ is a plasma-creating gas, which excepts forming of $(\mathrm{CFCl})_{\mathrm{FG}}$ groups in the third area. There a creation of a polymer layer is possible, which is built by $\mathrm{C}, \mathrm{F}$ and $\mathrm{Cl}$ atoms at a certain quantity proportion. Namely, their quantity proportion defines the saturated value of $W_{A}$ at the long times of treatment $\left(t_{t r} \geqslant 100 \mathrm{~s}\right)$.

This analysis shows that, in order to interpret the experimental results, at least the following kinetic processes should be included, which are connected with the creation and destruction of:

- different oxygen-containing $(\mathrm{O})_{\mathrm{FG}}$ functional groups;

- different carbon-hydrogen $(\mathrm{CH})_{\mathrm{FG}}$ functional groups;

- carbon-chlorine $(\mathrm{CCl})_{F G}$ functional groups;

- different carbon-fluorine-chlorine $(\mathrm{CFCl})_{\mathrm{FG}}$ functional groups. 


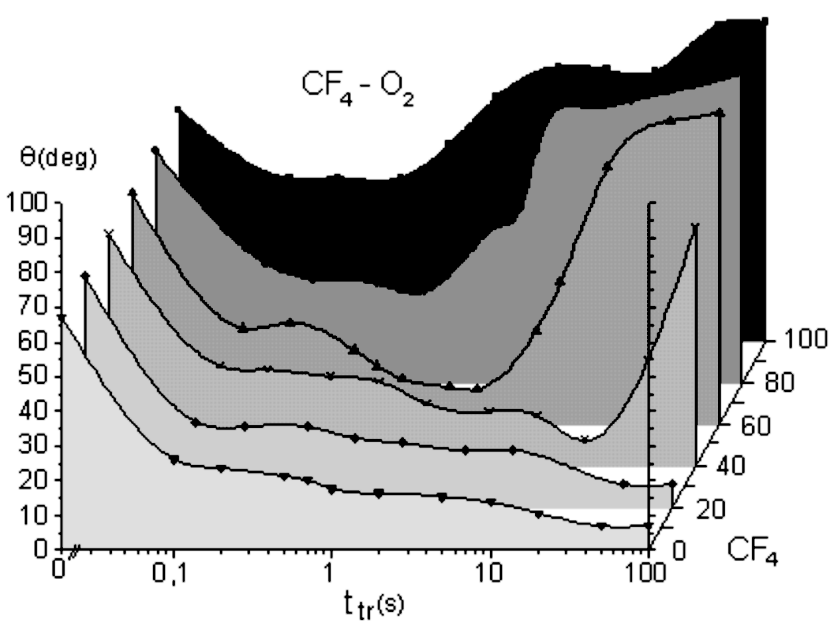

Figure 5. Behavior of the contact angle $\theta$ at the treatment time $t_{t r}$ for different percentages $\mathrm{CF}_{4}-\mathrm{O}_{2}$.

As a result of the treatment of the polymer surface in the RF-discharge, the type of the receiving functional groups will be defined out of the character rate constant and its describing kinetic chemical equations, etc.

Similar behavior of changing the contact angle $\theta$ and work of adhesion $W_{A}$, is also observed in the mixture $\mathrm{CF}_{4}-\mathrm{O}_{2}$, Figsures 5 and 6 . For the researched values of freon 14 with percentage proportion above $20 \%$, the work $W_{A}$ passes through a maximal value. With the decreasing percentage contents of $\mathrm{CF}_{4}$, the maximal value increases and is displaced by longer times $t_{t r}$. When the percentage content is less than $20 \%$, the change in the work $W_{A}$ is similar to that of pure oxygen. For this mixture, as well as in $\mathrm{Ar}-\mathrm{O}_{2}$ mixtures, high influence of the oxygen is observed in contrast with $\mathrm{CF}_{2} \mathrm{Cl} 2-\mathrm{O}_{2}$ mixtures. This is so even when impurity gases, as a result of gas emission in the reactor, assure its quantity. At the short $t_{t r}$, the work $W_{A}$ increases due to created oxygen-containing $(\mathrm{O})_{F G}$ groups, which dominate above other groups. After the work $W_{A}$ passes through the extremum, carbon-fluorine $(\mathrm{CF})_{\mathrm{FG}}$, groups type $\mathrm{CF}_{3}, \mathrm{CF}_{2}$ and $\mathrm{CF}$ begin to dominate, which displace $(\mathrm{O})_{\mathrm{FG}}$ groups, too. The higher the percentage contents of freon 14 the faster the increase in the concentration of $(\mathrm{CF})_{\mathrm{FG}}$ and the initiation of this process is faster.

The increase in the concentration of fluorine $(\mathrm{CF})_{\mathrm{FG}}$ groups can lead to the creation of a polymer layer at the long times $t_{t r}$, which is built basically by $\mathrm{C}$ and $\mathrm{F}$ atoms at a certain quantitative proportion which defines the saturated value of $W_{A}$. As it is the case in [1], here we can also observe an unstable state of the pattern water drop, after it is put on the treated surface in the mixture $\mathrm{CF}_{4}-\mathrm{O}_{2}$. That state is assigned to the gas mixture, which contains $\mathrm{CF}_{4}$ from $100 \%$ to $40 \%$ 


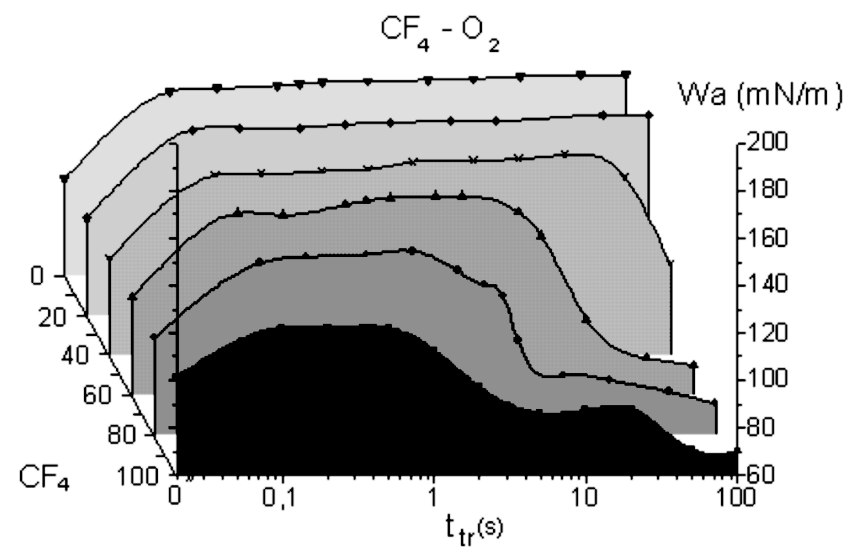

Figure 6. Behavior of the adhesion work $W_{A}$ at the treatment time $t_{t r}$ for different percentages $\mathrm{CF}_{4}-\mathrm{O}_{2}$.

where decrease in the work $W_{A}$ is observed. The reason that could be pointed is the rising polymer layer from the created carbon-fluorine $(\mathrm{CF})_{\mathrm{FG}}$ groups, as they are created in the oxygen-containing $(\mathrm{O})_{\mathrm{FG}}$ groups. When the pattern liquid is put, then that layer is destroyed and the contact angle $\theta$ sharply decreases. The new value of the angle $\theta$ is near to the value of $\theta$, which is got after polymer treatment in oxygen environment. It shows that below the grown $\mathrm{CF}_{4}$ groups in that case the $(\mathrm{O})_{\mathrm{FG}}$ groups created earlier are still present. The interval of the time $t_{t r}$, wherein is shown in the second spilling of the drops, is different and depends on the percentage proportion of the gas mixture. It coincides with the interval, where the carbon $(\mathrm{CF})_{\mathrm{FG}}$ groups begin to displace $(\mathrm{O})_{\mathrm{FG}}$ groups and to rise the polymer layer. After a certain time of treatment $t_{t r}$ a low change in the work $W_{A}$ (angle $\theta$ ) is reached and there is a tendency for saturation. These values of $W_{A}$, as it was discussed, are close to the dimension of the values of fluorine-hydrogen polymers. At the measuring in that area of saturating, the pattern drop does not spill any more and it stays quasi-stationary at the time.

The following kinetic processes will describe one possible interpretation of the experimental results for that mixture. These processes are connected with the creation and destruction of:

- different oxygen-containing $(\mathrm{O})_{\mathrm{FG}}$ functional groups;

- different carbon-hydrogen $(\mathrm{CH})_{\mathrm{FG}}$ functional groups;

- different carbon-fluorine $(\mathrm{CF})_{\mathrm{FG}}$ functional groups.

On condition that it is necessary to be included the rising of a polymer layer at the third area of the time of treatment $t_{t r}$, then to the creation and destruction 
of the functional groups should be included kinetic equations. These equations describe polymerization on the polymer surface.

\section{Conclusion}

Despite the difference in the behavior of the adhesion work $W_{A}$ (angle $\left.\theta\right)$, which is due to the use of a mixture of various gases, the process of polymer surface modification enables non-complicated schemes to be reduced and they allow the interpretation of the qualitative experimental results.

At the short and middle times of treatment $t_{t r}$ (conventionaly accepted as first and second areas), these kinetic processes are responsible for the creation and destruction of defined functional groups. In this case we can speak about modification by replacement according to the accepted terminology in [1]. Some specific functional groups are depending on the chemical composition of the mixture, but common functional groups participate in all mixtures. We accepted two functional groups as:

- oxygen-containing $(\mathrm{O})_{\mathrm{FG}}$ functional group, which is due to the oxygen and its compounds in researching mixtures,

- carbon-hydrogen $(\mathrm{CH})_{\mathrm{FG}}$ functional group, which is due to the treated organic polymer material in the RF-discharge.

The interaction between the functional $(\mathrm{O})_{\mathrm{FG}}$ group and pattern liquid is through the hydrogen bond. So, the change in $(\mathrm{O})_{\mathrm{FG}}$ will lead to a change in the polar component of the surface tension $\sigma_{s v}^{p}$. The interaction between the functional $(\mathrm{CH})_{\mathrm{FG}}$ group and the same liquid is through dispersion of van der Waals interaction. In this case, the change in $(\mathrm{CH})_{\mathrm{FG}}$ will lead to a change in the dispersion component $\sigma_{s v}^{d}$. The result is that both groups will define surface tension $\sigma_{s v}$ of the polymer when it is changing, with a change in the time $t_{t r}$.

In $\mathrm{Ar}_{-} \mathrm{O}_{2}$ mixture, the modification by replacement can be described through the two functional groups above mentioned. For the other two mixtures, more should be added:

- carbon-chlorine $(\mathrm{CCl})_{\mathrm{FG}}$ functional group;

- carbon-fluorine-chlorine $(\mathrm{CFCl})_{\mathrm{FG}}$ functional group, for $\mathrm{CF}_{2} \mathrm{Cl}_{2}-\mathrm{O}_{2}$ mixture and

- carbon-fluorine $(\mathrm{CFCl})_{\mathrm{FG}}$ functional group, for $\mathrm{CF}_{4}-\mathrm{O}_{2}$ mixture.

At the long time of treatment $t_{t r}$ (third area), the kinetic scheme is changed. In Ar- $\mathrm{O}_{2}$ environment, where modification by etching is realized, it is necessary to involve some models, which describe the etching processes. In polymer creating 


\section{M. Svirachev, N. A. Tabaliov}

environment $\left(\mathrm{CF}_{2} \mathrm{Cl}_{2}-\mathrm{O}_{2}\right.$ and $\left.\mathrm{CF}_{4}-\mathrm{O}_{2}\right)$, modification by polymerization is realized. In that case it is also necessary to involve some models, which describe the polymerization processes.

The treatment of the polymer material in pure gases $\left(\mathrm{Ar}, \mathrm{CF}_{2} \mathrm{Cl}_{2}, \mathrm{CF}_{4}\right)$ should be interpreted with the same kinetic schemes, as well as for their mixtures with the oxygen. This is so, because the experimental technology, which is used, allows even small quantities of oxygen-containing gases, but unfortunately, they are not enough for participation of polymer modification. More detailed investigation of these processes in pure gases is needed. Therefore it is necessary to use the technology of the experiment at the level of the ultra high vacuum.

The analysis we have tried to do with the so accepted kinetic processes, which take place at the plasma modification in the RF-discharge, and the accepted functional groups, which are created on the polymer surface at this treatment, are a precondition for the creation of a quantitative model. The successful solution of a similar task will describe the quantitative characteristics of the researched case. Moreover, the type of the theoretical behaviors is a base for the statistical treatment of the experimental results of adhesion work $W_{A}$ and contact angle $\theta$.

\section{References}

[1] D.M. Svirachev and N.A. Tabaliov, (to be published).

[2] F.D. Egitto (1990) Puer Appl. Chem. 651699.

[3] R. d'Agostino, P. Capezzuto, G. Bruno and F. Gramarossa (1985) Puer Appl. Chem. 571287.

[4] A.M. Wrobel, B. Lamontagne and M.R. Wertheimer (1988) Plasma Chem. Plasma Process. 8315.

[5] E.M. Liston and P.W. Rose (1985) Proceedings of the 7th International Symposium on Plasma Chemestry, Eindhoven, 219.

[6] R. d'Agostino, F. Gramarossa and S. de Benedictis (1982) Plasma Chem. Plasma Process. 213.

[7] G. Turbon and M. Rapeaux (1983) J. Electrochem. Soc.: Solid-State Sci. Technol. 1302231.

[8] M. Morra, E. Occhiello and F. Garbassi (1990) Adv. Colloid Interface Sci. 3279.

[9] J. Kloubek (1992) Adv. Colloid Interface Sci. 3899.

[10] V.A. Godyak, R.B. Piejak and B.M. Alexandrovich (1991) IEEE Trans. Plasma Sci. 19660.

[11] B. Eliasson and U. Kogelschatz (1991) IEEE Trans. Plasma Sci. 191063.

[12] A.W. Neumann and RJ. Good (1979) Surface and Colloid Science eds. R.J. Good and R.R. Stromberg, 11, Experimental Methods; Plenum Press, New York, 31.

[13] B.V. Summ and Ju.V. Gorjunov (1976) Physicochemical bases of the wetting and spreading; Chem. Press, Moscow, (in Russian). 